\title{
Power Generation Using Speed Breakers
}

\author{
Shehar Bano*, Anns Nadeem, Abrar Ahmad, Umer Shuja \\ Department of Electrical Engineering, HITEC University, Taxila, Pakistan \\ Corresponding author, e-mail: sherri.ali159@gmail.com*, anns.shah41@gmail.com, \\ Abrar_11ee007@yahoo.com, syedumarshuja@ymail.com
}

\begin{abstract}
In the current scenario demand of power is increasing day by day with increasing population. On the other hand energy crisis is also a main issue of today's life and all there is a shortage of conventional energy resources due to its large usage. So, we have to sort out this problem with a technique which will not only overcome this energy crisis but also should be eco-friendly. Many conventional resources are creating pollution so that's why focus is towards eco-friendly solution. This project emphasizes on idea which shows that power could be generated by specially designed speed breakers. A large amount of kinetic energy is being wasted on roads on daily basis in different forms which could be use to generate power and this power can be stored in batteries. This project shows clearly how we can generate power by using rack-pinion method where basically linear motion is converted into rotatory motion and then can be used to generate electricity. Large amount of electricity can be generated using this method and this method is eco-friendly.
\end{abstract}

Keywords: energy crisis, kinetic energy, power production, speed breakers.

Copyright $(2015$ Institute of Advanced Engineering and Science. All rights reserved.

\section{Introduction}

Energy crisis is one of the main problems and issues which are under focus these days. We have shortage of conventional resources of energy and most conventional resources like fossil fuels etc are not eco-friendly and also cause pollution. Now it's time to move towards solution of energy crisis with the factor in mind that solution should be eco-friendly.

As population of the world increasing rapidly, vehicles which are related to population are also increasing on roads. When vehicle passes over the road a large amount of energy is being wasted in different forms e-g friction, kinetic energy. We can make use of this energy and could generate power. In back days this method was of not much importance because relatively energy wasted on roads was not much but now due to high population and high traffic on roads this wasting energy is of much importance and should be focused upon.

Specially designed speed breakers could be implemented on roads which can generate power when any vehicle passes over them. When vehicle passes over the speed breaker it presses it down and due to Rack-Pinion this linear motion is converted into rotory motion and then this rotory motion can be used to operate DC generator to produce electricity. Batteries are used to save the energy and DC could be converted into AC using inverter. This project could be implemented on roads where there is heavy traffic.

As an example, according to statistics provided by the Provincial Excise \& Taxation Departments, Government of Pakistan, there is a heavy vehicular growth as shown in Figure 1; there were approximately 4.78 million vehicles on roads in 2001 and this figure reached to 7.86 million in 2010. So we can use this opportunity and energy to generate power.

In order to solve this problem of energy crisis a project is made by us, which is using speed breaker to produce eletricity. A special proto-type of speed breaker was made by us and was implemented on the road and under speed breaker. Rack-Pinion mechanism was used in this project. When vehicles passes over these specially designed speed breakers then due to rack pinion linear motion is converted into rotory motion. Rotory motion then can be used to rotate the shaft of dynamo or generator. Power generation by this method has many advantages because it is eco-friendly method and generation is through out the year. 


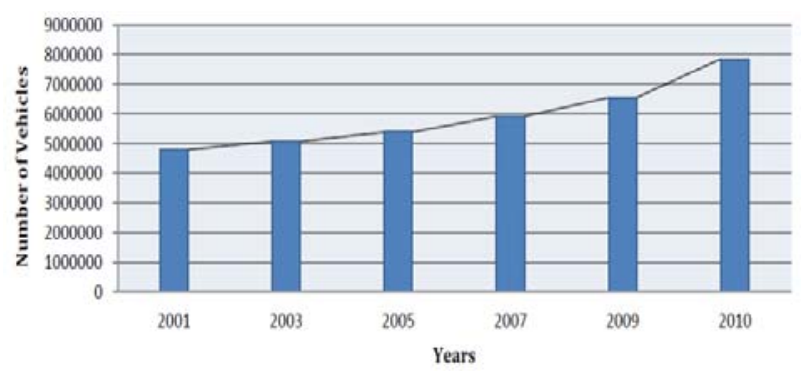

Figure 1. Traffic density in Pakistan in Last decade [1]

This paper completely describes the method and working of power generation using speed breakers. In first section there is an introduction related to power generation using speed breakers. In second section literature review is represented regarding this project. Third section illustrates methodology and working of project. In fourth section results are ellaborated and output power calculations are shown. In last section conclusion and some future directions are given.

\section{Literature Review}

This paper focuses on mechanisim of electricity generation using speed breakers. There are many methods to produce electrcity using speed breakers like Roller, Rack-Pinion, Crank shaft etc. This paper is based upon the project which has rack-pinion mechanism. we are going to outline the significant studies devoted to this topic.

Singh et al. [2] discussed rack pinion mechanisim to generate electricity. They proposed mechanism using chain aporocket and springs with rack pinion to generate electricity. Vehicle was passed over that mechanism and then due to rack pinion there was rotation in gears and shafts moved with chain sprocket movement. Dc power was generated and was stored in a battery and then using an inverter they changed that dc in ac power.

Das et al. [3] proposed mechanism in which electricity was produced by kinetic energy of speed breaker. The basic principle was when a car passes over the jump or dome which is the device use in place of jump the dome will go down due to weight of car while moving car possess kinetic energy that kinetic energy will be converted into rotational energy with the help of rack and pinion. A fly wheel was mounted on the shaft whose function was to make energy uniform. That shaft is connected through a belt with dynamos. These dynamos were used to convert mechanical energy in electrical energy. The power was generated in both directions. They used Zener diode to generate power in opposite direction too.

Kaur et al. [4], discussed mechanism of power generation with speed breakers by using rack and pinion technique. They made a dome like assembly to place under the speed breaker. When a car passed over this dome the rack will convert linear motion into rotatory motion with the help of pinion and pinion is connected to a shaft which will also rotate with the pinion. A large gear was also connected to the shaft which will also move and it will move with the same speed of pinion this gear is connected to another small gear using chain sprocket arrangement this will rotate the small gear and small gear will complete more rotations as compared to bigger one. A flywheel was mounted on the lower shaft whose function was to regulate the fluctuation in the energy and to make the energy uniform, now this shaft was connected to the generator using spur gear due to which the generator was rotated and the electricity was produced.

The project and mechanism which is explained in this paper is continuity of the mechanism of power generation. In this paper electrical portion is modfied by using microcontroller and sinosidal PWM inverter. Electrical circuitary is improved so that there should be less power losses across the mechanism and more power can be collected at the end.

\section{Method}

This project is based on two main parts, i-e Electrical and mechanical part. Working of this projects consists of three simple steps:

TELKOMNIKA Vol. 16, No. 3, December 2015: $417-422$ 
1) Conversion of kinetic energy into rotational energy

2) Conversion of rotational into mechanical

3) Conversion of mechanical into electrical

\subsection{Construction Details}

Main elements which are being used in this project are as below in Table 1.

Table 1. Specifications of components

\begin{tabular}{lc}
\hline \multicolumn{1}{c}{ Component } & Specifications \\
\hline Rack & $\begin{array}{c}37 \text { teeth, Mild steel } \\
\text { Total length } 355.6 \mathrm{~mm},\end{array}$ \\
\hline Spring & Yamaha front shock springs \\
\hline Shaft & Dia 25mm, Length 304.8mm \\
\hline Pinion( Small Gear) & Reverse gear, teeth 24, External dia $71 \mathrm{~mm}$, Internal dia 53mm \\
\hline Large gear & Teeth 110, External dia 257mm, internal dia 225mm \\
\hline Ball bearings & Type 6205 \\
\hline Dynamo & Bicycle dynamo(12V,6W) \\
\hline Fly Wheel & Weight 15.3 Kg, Diameter 250mm, Thickness 38.1mm \\
\hline Chain Sprocket & 3 chain sprockets for 3 dynamos \\
\hline DC Battery & $12 \mathrm{~V}$ \\
\hline Transformer & $12 \mathrm{~V} ~ 220 \mathrm{~V}$ \\
\hline
\end{tabular}

Inverter is designed using the components which are listed in Table 2.

Table 2. Inverter components

\begin{tabular}{lc}
\hline \multicolumn{1}{c}{ Component } & Specfications \\
\hline Microcontroller & PIC 16F877A \\
\hline Driver IC & IR2112 \\
\hline Regulators & 9V, 5V \\
\hline Diode & 1N4148 \\
\hline H-Bridge & Using MOSFETS IRF540 \\
\hline Heat Sinks & 4 heat sinks with MOSFETS \\
\hline
\end{tabular}

\subsection{Block Diagram}

Mechanism of the whole project could be seen in this block diagram given below.

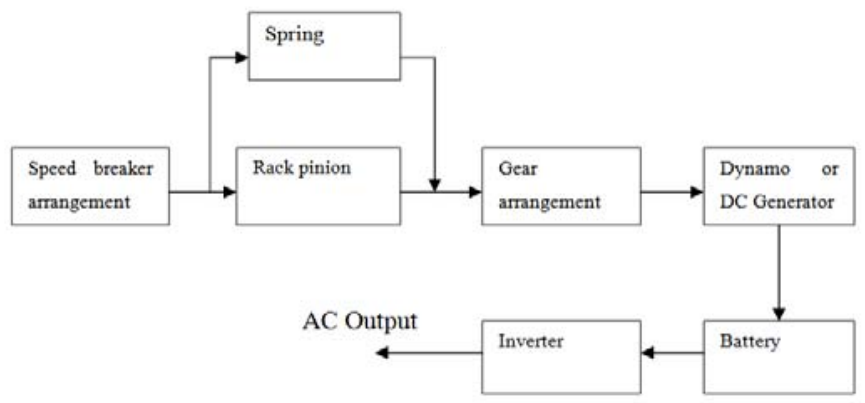

Figure 2. Illustration of mechanism with block diagram

This block diagram in Figure 2 illustrates the basic principle of our project in which first of all kinetic energy is changed into rotational energy using springs and rack pinion. Then this rotational energy is changed into mechanical energy using gear and shaft. In the end when shaft rotates due to its rotation DC generator or dynamo works and produce output in DC form. A battery is used which stores the DC output produced by dynamo and then in last an inverter is used which produces AC output. 


\subsection{Working}

Whenever a vehicle will pass over the speed breaker it will press it down. Rack will be press down due to vehicle weight and due linear movement of rack the pinion attached with the rack will rotate. This is how linear movement is changed into rotational movement. Pinion is attached with a shaft and that shaft has a gear on its other side which will also rotate. This gear is making a gear train with the smaller gear which is connected on other shaft and this will also rotate and rotating the second shaft. This shaft has a fly wheel on its other end which is used to ensure the constant rotational movement. Ball bearings are used to support the smooth rotation of shafts. A chain sprocket is also mounted on this shaft which is connected with the three dynamos and function of chain sprocket is to rotate the dynamos which are producing DC output. This DC is stored in a battery.

Battery used is $12 \mathrm{~V} \mathrm{DC}$. This battery is connected with the dynamos and whenever there is a vehicle passed over the speed breaker each dynamo is generating $12 \mathrm{~V}$ and $6 \mathrm{Watts}$. This $12 \mathrm{~V} \mathrm{DC}$ is stored in the battery and this is how mechanical portion works and converting kinetic energy into electrical energy. Figure 3 and Figure 4 shows the front and back view of mechanical portion.

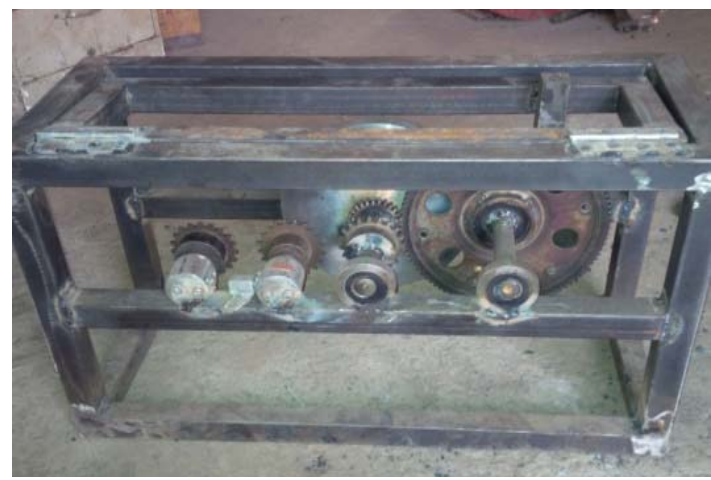

Figure 3. Front view of mechanical portion

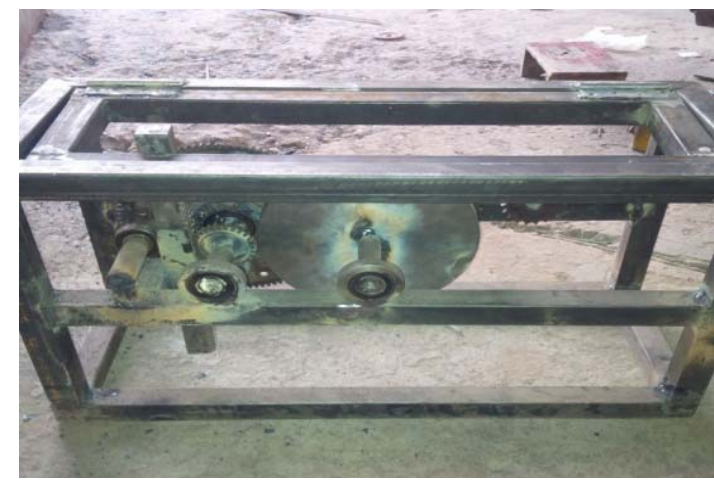

Figure 4. Back view of mechanical portion

We are getting $12 \mathrm{~V}$ output from dynamos which are stored in a battery. Output from this battery is given to regulators. There are two regulators, first regulator changes this $12 \mathrm{~V}$ into $9 \mathrm{~V}$ and second one changes $9 \mathrm{~V}$ into $5 \mathrm{~V}$ and gives it to microcontroller. Microcontroller has modified sinusoidal PWM inside. PWM wave from microcontroller is given to drivers and a driver is IR2112 IC. 5V VDD is given to drivers by microcontroller and $12 \mathrm{~V}$ is also given to drivers by DC battery. After drivers there is an $\mathrm{H}$-bridge made up of 4 MOSFETS.

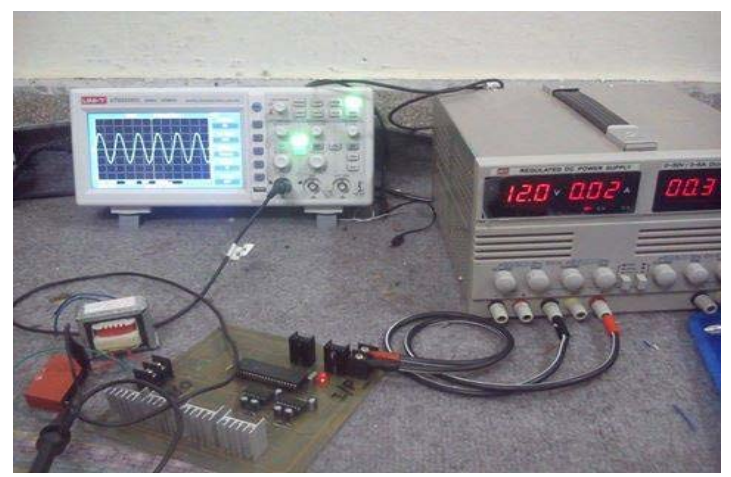

Figure 5. Electrical Circuitry

TELKOMNIKA Vol. 16, No. 3, December 2015 : $417-422$ 
MOSFETS are working as a switch means only in on and off mode [5]. $12 \mathrm{~V}$ is given to all MOSFETS. There is a heat sink with each MOSFET so that it can control heat dissipation from switching device [6]. From drivers $\mathrm{HO}$ i-e High Output is given to upper both MOSFETS of $\mathrm{H}$ bridge and LO i-e Low output is given to both lower MOSFETS. Output of $\mathrm{H}$-bridge is $12 \mathrm{~V}$ AC. A step up transformer is connected as a load with $\mathrm{H}$-bridge and is converting $12 \mathrm{~V} \mathrm{AC}$ into 220V AC.

In Figure 5 we can see the mechanism in working condition. A red LED is used in the circuit with microcontroller to detect if microcontroller is working or not. If microcontroller is working properly then LED will glow and if circuit is not working properly then LED will not glow.

\section{Results and Discussion}

The assembly was mounted under the speed breaker and a vehicle was passed over it. For one vehicle when ever speed breaker is completely pushed downwards $12 \mathrm{~V}$ DC is produced and $100 \mathrm{~kg}-150 \mathrm{~kg}$ atleast is required for complete push of this assembly.

\subsection{Output Power Calculations}

A Dynamo needs $250 \mathrm{rpm}$ to generate $12 \mathrm{~V} \mathrm{DC}$ and 6 Watts [7].

As we know that gear ratio between rack pinion is 1:1.5

For one complete push of rack, pinion moves 1.5 times.

Let,

There are 60 pushes of rack in one minute

Then,

For 60 pushes of rack there are $90 \mathrm{rpm}$ of pinion.

The shaft of pinion is rotating at $90 \mathrm{rpm}$ and big gear is also at $90 \mathrm{rpm}$.

For second gear train,

$\mathrm{Wp} / 90=110 / 24$

Where $\mathrm{Wp}=\mathrm{rpm}$ of pinion

$\mathrm{Wp}=412.5 \mathrm{rpm}$

Hence dynamos are taking 400 rpm approx.

So they are giving output of $12 \mathrm{~V}, 6$ Watts per dynamo.

There are 3 dynamos and they are giving 18 watts.

For one push of rack we have $12 \mathrm{~V} \mathrm{DC}$ and 18 Watts

\subsection{Output Results}

$12 \mathrm{~V}$ DC of battery is converted into $12 \mathrm{~V}$ AC using inverter and then a step up transformer is converting this $12 \mathrm{~V} \mathrm{AC}$ into $220 \mathrm{~V} \mathrm{AC}$. Charging time of the battery is 15 minutes i-e for 15 minutes if continuously there are vehicles passing over the speed breakers battery will be charged.

In Figure 6 a graph is shown between output power vs number of vehicles passed over the speed breaker.

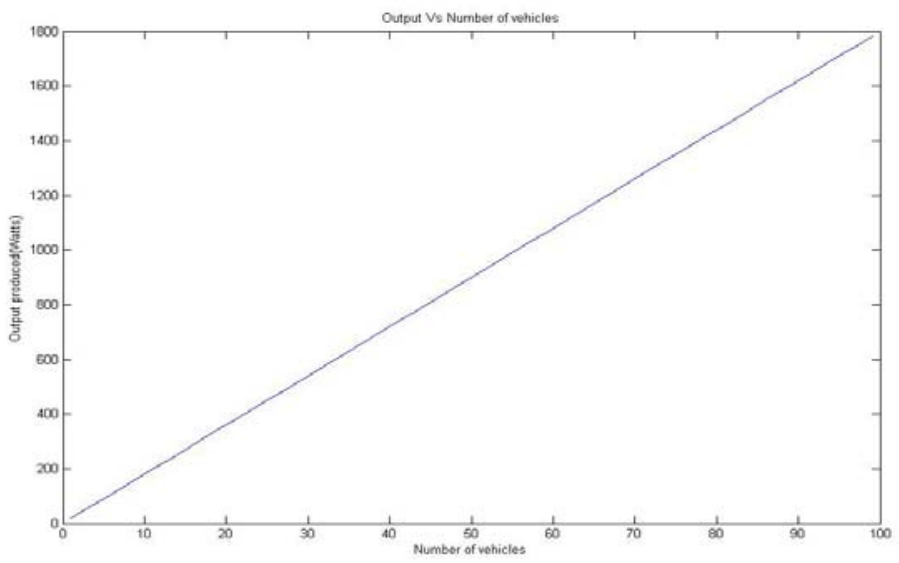

Figure 6. Output power vs number of vehicles 
Figure 6 shows the results, as 18 watts are produced for one push of spee breaker downwards. We can see that output power produced is directly proportional to number of vehicles passing over the speed breaker. This project can be used on roads where there is heavy traffic so more output power can be taken from this mechanism.

\section{Conclusion}

This project was about power generation using speed breakers. Energy is wasted on roads daily on a large scale. This project makes use of that energy and used it to produce electricity to overcome power shortage in Pakistan and rest of the world.

Cost factor was the major problem but in this project this problem was reduced to some extent by using dynamo instead of generator. Springs of Yamaha bike are used which are easily available and cost efficient. Inverter was designed to make this project power efficient.

Efficiency is improved by using shock springs and specially designed rack pinion due to which mechanism is able to bear more heavy vehicles. Dynamos are used with chain sprocket so installation and implantation problem is also solved. Whole mechanism is placed in a dome which can be placed anywhere.

\section{References}

[1] Ahmad Syed Arslan, Bilal Masood. Power Scavenging from Moving Vehicles on Road. International Journal of Innovation and Applied Studies. 2014; 9(4): 1428.

[2] Singh Alok Kumar, et al. Generation of Electricity through Speed Breaker Mechanism. International Journal of Innovations in Engineering and Technology IJIET. 2013; 2(2): 20-24.

[3] Das CK, Syed Monowar Hossain, MS Hossan. Introducing speed breaker as a power generation unit for minor needs. Informatics, Electronics \& Vision (ICIEV), 2013 International Conference on IEEE. 2013.

[4] Kaur Amanpreet, et al. with Auto Street Light. International Journal of Engineering Science and Innovative Technology (IJESIT). 2.

[5] http://www.mcmanis.com/chuck/robotics/tutorial/h-bridge/

[6] http://www.cadvision.com/blanchas/hexfet/

[7] http://www.voltaicsystems.com/blog/make-a-dynamo-to-charge-your-phone/ 